\title{
Eficiência x Equidade na tributação sobre o capital no Brasil
}

\author{
Efficiency x Equity in Taxation on Capital in Brazil
}

\author{
André Felipe de Carvalho Sanchez ${ }^{1}$ \\ Mauro Fernandes Gallo
}

\section{Resumo}

Esse trabalho tem por objetivo analisar a participação na arrecadação dos principais tributos sobre o capital na esfera federal na última década, buscando averiguar se existiu uma tendência a incentivar investimentos (eficiência) ou uma tendência a uma maior redistribuição (equidade). Visando alcançar esse objetivo, foi realizado um estudo exploratório e documental. Para o desenvolvimento do tema, abordouse o tradicional trade-off entre eficiência e equidade, e a Teoria da Tributação do Capital. Observou-se que, para os anos de 2004 a 2009, existiu uma tendência de redistribuição, já para os anos de 2010 a 2013, essa tendência de elevação deixou de ocorrer. Apesar disso, a participação dos tributos sobre o capital nos últimos quatro anos apresentou elevação quando comparada aos primeiros anos da análise. Contudo, quando o percentual de participação é analisado levando em consideração os aspectos históricos (2004-2013), são encontradas algumas particularidades, justificadas principalmente pelo fato de que o governo federal, mesmo que opte por

Mestrando em Ciências Contábeis pela Fundação Escola de Comércio Álvares Penteado (FECAP), Pós-graduado em Controladoria pela FECAP (2014). Possui graduação em Ciências Contábeis pela Faculdade de São Vicente (2011) - (Conceito 4 ENADE). Atualmente é Contabilista na PETROBRAS, Professor Universitário no Centro Universitário Adventista de São Paulo (UNASP) e Professor de Pós Graduação (visitante) na Universidade Santa Cecilia (UNISANTA) em Santos - Brasil - E-mail: andrefsanchez1@hotmail.com

2 Possui graduação em Ciências Econômicas pela Faculdade de Ciências Econômicas de São Paulo (1975), mestrado em Controladoria e Contabilidade Estratégica pelo Centro Universitário Álvares Penteado (2002) e doutorado em Controladoria e Contabilidade pela Universidade de São Paulo (2008). Foi professor pesquisador do curso de Mestrado em Ciências Contábeis da Fundação Escola de Comércio Alvares Penteado de 2008 a 2015. Atualmente é sócio da Gallo Planejamento Ltda.; professor nos cursos de pós-graduação da FIPECAFI (FEA/USP), da FUNDACE (FEARP/USP) e do IPOG; suplente do Conselho Municipal de Contribuintes da Prefeitura Municipal de Bauru e pesquisador do Núcleo de Estudos de Gestão Tributária da FEA/USP. Tem experiência nas áreas de Administração, Economia e Ciências Contábeis, atuando principalmente nas seguintes áreas: Gestão e Planejamento Tributário, Contabilidade Tributária e Economia do Setor Público. É autor de diversos livros sobre gestão tributária, bem como de artigos científicos nas áreas contábil e tributária, publicados no Brasil e no exterior Brasil - E-mail: maurogallo@uol.com.br 
eficiência ou por equidade, poderá se deparar com cenários aos quais será preciso adaptar-se ou adotar determinada ação. O fim da CPMF e a crise internacional são exemplos no período estudado.

Palavras-chave: Economia do Setor Público. Teoria da Tributação do Capital. Eficiência. Equidade.

\section{Abstract}

This paper aims to examine the participation in the collection of the main taxes on capital at the federal level in the last decade, seeking to ascertain whether there was a tendency to encourage investment (efficiency) or a trend toward greater redistribution (equity). In order to achieve this goal, it performed an exploratory and documental study. To the topic of development, it was addressed to the traditional trade-off between efficiency and equity and the Theory of Capital Taxation. It was observed that, for the years 2004-2009, there was a tendency to redistribution, as for the years 2010 to 2013, this upward trend ceased to occur. Nevertheless, the share of taxes on capital in the last four years showed an increase compared to the first years of the analysis. However, when the percentage of ownership is analyzed taking into account the historical aspects (2004-2013), are found some particularities, justified mainly because of the federal government, even if you choose for efficiency or equity, may encounter scenarios which will have to adapt or adopt certain action, the end of the CPMF and the international crisis are examples of the study period.

Keywords:Public Sector Economics. TheoryofCapitalTaxation.Efficiency.Equity.

\section{Introdução}

A tributação influencia na alocação dos recursos na economia, transferindo-os das empresas para os órgãos públicos. O Estado utiliza esses recursos alocando-os na sociedade, porém, esse processo gera uma perda de parte deles, denominada peso morto, acarretando em ineficiência. Como razão disso, temos os custos de administração dos recursos.

No tradicional trade-off entre eficiência e equidade, a busca da equidade e redistribuição na alocação dos recursos por parte do Estado traria menor eficiência econômica e mudanças no comportamento por parte dos investidores, devido a um capital mais tributável. O capital tem sido apontado como um dos principais determinantes do crescimento 
econômico, demonstrando relação entre o nível de investimento e formação da poupança com o processo de desenvolvimento das nações.

De acordo com a Teoria da Tributação do Capital, uma menor incidência sobre o fator capital acarretaria em uma maior formação de poupança e investimentos, levando a um maior desenvolvimento econômico.

Diante do exposto, elaborou-se o seguinte questionamento: qual a participação do IRPJ/CSLL e IRRF sobre rendimento do capital na arrecadação total do governo federal, no período de 2004 a 2013 ?

A presente pesquisa tem como objetivo geral analisar a participação na arrecadação dos principais tributos sobre o capital na esfera federal durante a última década, buscando averiguar se existiu uma tendência a incentivar investimentos (eficiência) ou a uma maior redistribuição (equidade). No sentido mais específico, objetiva analisar qual a participação na arrecadação do Imposto de Renda Pessoa Jurídica (IRPJ); na Contribuição Social sobre o Lucro Líquido (CSLL) e no Imposto de Renda Retido na Fonte (IRRF) sobre o rendimento do capital em relação à arrecadação total dos tributos obtidos pela Receita Federal do Brasil, no período de 2004 a 2013, buscando averiguar se existiu uma tendência a incentivar investimentos (eficiência) ou uma tendência a uma maior redistribuição (equidade), segundo a Teoria da Tributação do Capital.

A importância deste estudo pode ser justificada principalmente pela escassez de trabalhos científicos que tratem exclusivamente da tributação sobre o capital sob a ótica governamental e da análise de seu reflexo na economia e sociedade brasileira. Será possível demonstrar se a Teoria da Tributação do Capital, de fato, exerce influência em relação ao período pesquisado, uma vez que, dentro do período estudado, políticas econômicas e sociais de determinados chefes de Estado e seus parlamentares podem ter influenciado as variações dos percentuais de participação dos tributos sobre o capital. 


\section{Referencial teórico}

Nesta seção, serão tratados os temas que darão suporte teórico para o estudo aqui realizado. Inicialmente, será abordada a teoria da regulação e sua relação com o Estado; posteriormente, serão demonstradas as influências tributárias na alocação de recursos e o tradicional trade-off entre eficiência e equidade. Por último, será apresentada a Teoria da Tributação do Capital.

\subsection{Teoria da Regulação}

A Teoria da Regulação é formada na visão de que o governo, com seu poder de coerção, pode afetar o processo de decisão dos agentes econômicos, principalmente nos setores de infraestrutura (como transportes, energia e comunicações) ou em estruturas de mercados significativos e/ou em desenvolvimento. A teoria tradicional da regulação assumia no início dos anos 1970 que, em setores de monopólio natural nos quais existem fortes economias de escala, que por sua vez se sustentavam na busca de eficiência, e exista apenas uma empresa, o governo deveria regular a indústria para que ela não se utilize de preços de monopólio. Segundo Fiani (1998, p. 30):

Os fatores históricos indicam que a discussão da atividade regulatória do Estado deve ser aprofundada considerando-se as características da fase em que se encontram as sociedades capitalistas, sejam avançadas ou em desenvolvimento, sob pena de produzir conclusões superficiais, pouco esclarecedoras das tendências em vigor e das questões colocadas a cada momento.

Na análise econômica da Teoria da Regulação, é avaliada a questão de abuso de poder e monopólios, pois setores com características técnico-econômicas específicas dificultam a existência de concorrência. Assim, Barrionuevo Filho e Lucinda (2004, p. 48) comentam que "para evitar que a situação de domínio de mercado propicie o abuso contra o direito de outros, seja de consumidores ou de empreendedores que gostariam de prestar esses serviços, o Estado intervém”. 
Essa intervenção é realizada por meio dos instrumentos de regulação, que são utilizados pelo governo para intervir no funcionamento econômico de acordo com seu poder de coerção, podendo ser pelo controle de preços, controle de quantidade comprada, controle de quantidade vendida e controle da taxa de retorno.

Outra linha dentro dessa teoria relata que a regulação por parte do Estado será exercida levando em consideração os interesses dos agentes políticos, que buscarão criar mecanismos de forma a arquitetar uma elevação de seu próprio poder (STIGLER, 1971).

Uma prática muito utilizada na intervenção econômica no Brasil está no controle de preços, principalmente com o objetivo de manter a inflação dentro do limite máximo do teto da meta de inflação. Um grande artifício utilizado pelo governo desse país é realizado por meio de sua principal estatal, a empresa de economia mista Petrobras. Quando fica obrigada a comprar combustível para suprir o mercado interno a preços maiores do que é praticado na revenda, ou seja, ela apresenta grande prejuízo nas suas atividades de distribuição, fazendo com que acionistas sejam prejudicados por essa prática. Contudo, o governo entende que a intervenção é necessária por conta do controle inflacionário, o qual, nos últimos anos, apresenta-se próximo do teto da meta. Assim sendo, caso a Petrobras tivesse autorização para repassar ao preço esse prejuízo, a inflação ultrapassaria o teto da meta estabelecida.

\subsection{Alocação de recursos pela tributação}

A tributação influencia a alocação dos recursos na economia, modificando a maneira como esses recursos seriam aplicados caso inexistisse a tributação. De acordo com Viol (2005, p. 9), existem três razões para essa influência na alocação econômica:

Primeiro, a tributação transfere recursos do setor privado para o público, que têm diferentes prioridades na alocação de recursos. Em segundo lugar, suas regras geram distorções na alocação de recursos privilegiando as atividades mais incentivadas em termos relativos. $\mathrm{E}$, 
sua própria existência gera uma cunha que é a perda de peso morto do imposto, que acaba não sendo alocada.

Uma vez descartada a condição de neutralidade em relação à política tributária e à alocação de recursos, cabe ao setor público utilizar com eficiência essa importante ferramenta, buscando incentivar o desenvolvimento econômico, uma vez que, não o fazendo, estará prejudicando a competitividade das empresas e não maximizará o bem-estar social. A gestão púbica ao redor do mundo também tem um importante impasse quanto à centralização ou descentralização da gestão fiscal, indubitavelmente esse é um tema que gera diversas opiniões pelos estudiosos, e que, pode interferir no aumento ou diminuição do "peso morto".

No Brasil, país classificado como em desenvolvimento, encontram-se diversas divergências quanto à alocação dos recursos, tanto por conta da política tributária adotada, como pela ineficiência nos serviços públicos oferecidos, principalmente nos de saúde e educação, prejudicando o bem-estar social e gerando reflexos quanto à taxa de mortalidade e o nível de qualificação e produtividade do trabalhador desse país, apesar da obrigação de aplicação em saúde e educação conforme determina a Lei de Responsabilidade Fiscal. Quanto à política tributária, o Brasil está entre os três países com a maior carga tributária da América Latina, atingindo $36,3 \%$ do PIB no exercício de 2012, sendo o segundo país com a maior carga tributária da América Latina, segundo dados da Organização para a Cooperação e Desenvolvimento Econômico (OCDE).

\subsection{Eficiência e equidade}

Essa seção trata do trade-off entre eficiência e equidade, em que, teoricamente, a busca de equidade e redistribuição, ao menos a curto prazo, traria menor eficiência econômica. Essa ineficiência se daria, por exemplo, pelos custos administrativos que envolveriam o processo de redistribuição por parte do governo ou por mudanças comportamentais por parte de investidores, devido a um capital mais tributável. Uma 
corrente dirá que o fator capital tem que ser onerado, uma vez que provavelmente terá mais condições de suportar a tributação. Contudo, outra corrente defenderá que o fator capital precisa ser menos onerado, ou sequer onerado, pois será o capitalista que fará os investimentos necessários para o desenvolvimento econômico.

Outro problema que seria gerado pelas políticas redistributivas está no fato de que o repasse de recursos venha a contemplar cidadãos que não carecem de tal benefício, mas que não se negarão a recebê-lo, ou que não beneficie os que realmente deveriam estar cadastrados nos programas sociais. O Brasil criou programas de redistribuição de renda que de fato atingem as classes sociais menos favorecidas economicamente, como é o caso do Programa Bolsa Família, regulamentado através da Lei Federal $n^{0} 10.836$, de 2004, que beneficia financeiramente famílias na faixa de extrema pobreza.

Contudo, o programa é constantemente questionado por estudiosos, tendo em vista que, uma vez incluso, o cidadão tende a permanecer nele, e por contar com uma administração descentralizada, fiscalizado pela Controladoria Geral da União (CGU). Já houve vários episódios em que até mesmo familiares de políticos com rendas superiores foram incluídos no programa, recebendo o benefício.

Também é importante mencionar que se tem encontrado na literatura um incentivo a uma maior redistribuição de renda em países como o Brasil. Estudos concluem que uma maior equidade contribuiria para o desenvolvimento econômico. Coutinho (2005, p. 8), comenta que algumas conclusões desses estudos, "ainda que não absolutamente consistentes entre si, apontam com cada vez mais clareza para a superação da ideia de que o crescimento leva à desigualdade".

O Brasil possui grandes problemas sociais, e na necessidade de distribuir renda e ao mesmo tempo estimular o desenvolvimento econômico, acaba precisando de mais recursos. Isso acaba elevando a carga tributária sobre o consumo, o que gera regressividade e o enfraquecimento da própria distribuição da renda. "A teoria econômica dá pouca orientação sobre de que maneira a equidade ou justiça devam 
ser incorporadas ao sistema fiscal e de transferência" (FORTIN, 2000, p. 6, tradução nossa).

A literatura recente sobre a tributação indireta tem sido caracterizada por duas vertentes independentes. Por um lado, há os defensores da substituição dos impostos indiretos diferenciadas por um imposto uniforme sobre todas commodities (como um imposto sobre o valor adicionado). O caso é baseado em grande parte na crença de que um imposto uniforme é mais propício para a eficiência econômica. Por outro lado, há também na literatura sobre "A tributação mercadoria ideal", argumentando que diferentes mercadorias devem ser tributadas a taxas diferentes, uma vez que este reduz a perda de peso morto. Essa linha de argumentação, que foi apresentada pela primeira vez por Ramsey (1927) e, posteriormente, prorrogada por Samuelson (1951), tem sido alvo de trabalhos recentes. (ATKINSON; STIGLITZ, 1972, p. 97, tradução nossa).

Na literatura, quanto ao melhor sistema de tributação, percebe-se que a ótima estrutura é discutida ainda nos dias de hoje. Possivelmente existe o modelo ideal, contudo, devem-se levar em consideração os aspectos culturais, sociais e econômicos de cada país. Os modelos ou as análises comparativas precisam ser realizados respeitando essa premissa, e ainda é possível ser identificado algum tipo de aversão, por determinada sociedade, em relação aos tipos de tributação, pois poderá ser mais oneroso tributar a renda do trabalhador do que tributar o consumo, ainda que esse modelo demonstre ser o ideal. Infelizmente, questões políticas podem gerar interferência quanto ao modelo, uma vez que o gestor público possivelmente buscará aderir ao perfil daquela sociedade, pois ele busca muitas vezes o próprio interesse, que no caso está em manter sua legitimidade e governabilidade. "Assim, na decisão do trade-off da política tributária entre equidade e eficiência, a sociedade tem, sistematicamente, demonstrado sua preferência pelo primeiro." (VIOL, 2005, p. 11). 
Indubitavelmente, outro fator político que interfere na adoção de um ótimo modelo tributário dentro de determinado país está relacionado com a "corrente partidária", ou seja, a estrutura partidária que envolve o gestor público. Sobre um governante de uma legenda partidária que tem como fundamento o socialismo, por exemplo, é possível supor que fará preferência por uma política econômica mais voltada para a redistribuição e equidade.

\subsection{Teoria da Tributação do Capital}

O capital tem sido apontado como um dos principais determinantes do crescimento econômico, demonstrando relação entre o nível de investimento e formação da poupança com o processo de desenvolvimento das nações. Ao longo da segunda metade do século passado, encontram-se pesquisadores que trataram da tributação sobre o fator capital. Cordes e Sheffrin (1981) relatam os principais estudos na época, as contestações e dificuldades empíricas:

A estrutura atual do imposto de renda corporativo e pessoal, tradicionalmente, acredita-se que distorcem a alocação de capital entre os diferentes setores da economia. Esta visão é baseada em modelos de equilíbrio geral de incidência de imposto inicialmente desenvolvidas por Harberger e atualizados pelo Shoven (1976). A visão foi questionada por Stiglitz (1973, 1976), que argumentou que o comportamento financeiro das empresas é um elemento importante para uma análise completa. [...] Feldstein e Slemrod (1980) também reavaliou a incidência do imposto de renda de pessoa jurídica, estenderam a análise de Harberger (1962) para uma economia com dois grupos de proprietários de capital, um grupo que enfrenta altas taxas de impostos marginais sobre rendimentos de capital, outro que enfrenta baixas taxas de imposto, o estudo mostrou que para alguns titulares de ações de empresas, impostos sobre as sociedades mais impostos sobre dividendos e sobre ganhos de capital pode ser menor. Para esses investidores, investimentos de capital das empresas 
seria uma forma de abrigo de imposto, e as corporações teriam um incentivo a financiar investimentos com capital próprio. (CORDES; SHEFFERIN, 1981, p. 419, tradução nossa).

Além desses pesquisadores, Gravelle (1983) demonstra estudos que "calculam as taxas efetivas de imposto sobre os diferentes ativos depreciáveis dentro o setor empresarial e como estas taxas de imposto alteram de acordo com as revisões fiscais recentes" (tradução nossa). E Boskin (1988) analisa o cenário econômico dos Estados Unidos nos anos 1980:

A lição da década de 1980 não é que devemos mudar radicalmente a novas leis fiscais, mas sim que devemos construir em suas realizações: alargar a base tributária para incluir mais consumo, preservando taxas marginais de imposto baixos e restaurando incentivos cuidadosamente orientados para a poupança e investimentos. (BOSKIN, 1988, p. 72, tradução nossa).

No Brasil, a tributação incide sobre o capital, principalmente sobre os rendimentos das aplicações em ativos financeiros ou lucros gerados pelas empresas, tributados pelo Imposto de Renda Pessoa Jurídica (IRPJ) e Contribuição Social sobre o Lucro Líquido (CSLL), ou dos tributados gerados pelo Imposto de Renda retido na fonte sobre ganhos de capital. De acordo com Lemgruber (2004), a tributação sobre o capital tem ensejado longas controvérsias teóricas, pois:

Se por um lado, o acúmulo de capital deveria ser estimulado para alavancar o crescimento do produto; por outro, seu padrão de acumulação tem sido visto como concentrador de renda. Em decorrência, tributa-se o fator capital com menor alíquota se o foco da política tributária apontar para a eficiência econômica, ou, com maior, se o objetivo for a equidade social. (LEMGRUBER, 2004, p. 207).

Entretanto, em uma economia altamente globalizada, fatores externos podem influenciar a tributação de determinado país sobre o 
fator capital, devido principalmente a chamada competição tributária, uma vez que os investidores serão atraídos por nações que lhe ofereçam menores encargos tributários. Segundo Rezende (1999, p.16):

A suficiência dos tributos, sob a ótica da geração dos recursos necessários para 0 atendimento das responsabilidades do Estado, também é afetada pelas limitações macroeconômicas associadas à sustentação do equilíbrio fiscal, exigindo esforços crescentes para aumentar a eficiência da administração pública de modo a manter a carga tributária global nos limites impostos pela competição internacional (REZENDE, 1999, p.16.)

Outra discussão está em quem de fato arcaria com a tributação sobre o capital, uma vez que ela poderia não necessariamente recair sobre os donos do capital e ser repassada para os consumidores ou trabalhadores. A explicação mais provável seria a absorção desse aumento de tributos pelo capitalista em curto prazo, contudo, posteriormente, o capitalista transmitiria esses encargos por meio do consumo ou do fator trabalho, a depender da elasticidade do setor.

Por fim, outro argumento encontrado na literatura está na possibilidade de que um baixo nível de tributação sobre o capital poderia supor uma maior regressividade do sistema tributário, pois os impostos sobre o consumo, que correspondem em grande parte da arrecadação do país, seriam regressivos. Por sua vez, um baixo capital tributável atenuaria essa regressividade.

\section{Metodologia}

Quanto à abordagem do problema, a pesquisa é qualitativa. Para Minayo, Deslandes e Gomes (2012 p. 21): "A pesquisa qualitativa responde a questões muito particulares. Ela se ocupa, nas Ciências Sociais, com um nível de realidade que não pode ou não deveria ser quantificado. Ou seja, ela trabalha com o universo dos significados, dos motivos, das aspirações, das crenças." 
Esta pesquisa é caracterizada como exploratória. De acordo com Gil (2002, p. 42): "Estas pesquisas têm como objetivo proporcionar maior familiaridade com o problema com vistas a torná-lo mais explícito ou a constituir hipóteses. Pode-se dizer que estas pesquisas têm como objetivo principal o aprimoramento de ideias ou a descoberta de intuições."

O estudo foi realizado por meio de pesquisa documental. Segundo Martins e Theófilo (2009 p. 55), "a pesquisa documental emprega fontes primárias, assim considerados os materiais compilados pelo próprio autor do trabalho, que ainda não foram objeto de análise, ou que ainda podem ser reelaborados de acordo com os propósitos da pesquisa".

A pesquisa foi realizada coletando-se as bases de dados dos totais de tributos arrecadados pela Receita Federal do Brasil, do período de 2004 a 2013, disponibilizadas nas páginas eletrônicas dessa instituição. Posteriormente, foram realizados ajustes que se mostraram necessários para o estudo, entre eles, a exclusão: do Programa de Recuperação Fiscal (REFIS) e Parcelamento Especial de Débitos (PAES), ambos recebidos em 2004, porém de competências fiscais anteriores ao período analisado; dos pagamentos unificados de 2005; das receitas previdenciárias; das outras receitas administrativas; da Contribuição para o Plano de Seguridade Social dos Servidores Públicos; e das arrecadações administradas por outros órgãos.

Ainda optou-se por não compor no total dos tributos sobre o capital as arrecadações com o Imposto sobre Operações Financeiras (IOF), tendo em vista que esse imposto também inclui arrecadação sobre o consumo e a Receita Federal do Brasil não separa a parcela correspondente de cada tipo de arrecadação. Essa opção não prejudica o presente estudo, tendo em vista que a parcela sobre o capital desse imposto é irrelevante quando considerada com os impostos selecionados no cálculo.

$\mathrm{Na}$ execução dos cálculos, primeiramente, procurou-se o percentual dos tributos sobre o capital (IRPJ/CSLL/IRRF CAPITAL) em relação ao total dos tributos arrecadados de cada um dos anos, dados 
informados em reais $(\mathrm{R} \$)$; em seguida, os resultados foram analisados levando-se em consideração os aspectos históricos que pudessem influenciar a tributação no período pesquisado.

O estudo se limitou a demonstrar se existiu uma tendência em tributar mais o capital no período analisado. Levando-se em consideração as teorias até aqui expostas, buscou-se averiguar a existência de uma possível preferência entre eficiência e equidade, contudo, o presente estudo não aponta qual a tendência para os próximos anos.

\section{Discussão dos resultados}

Nesta seção, serão apresentados e discutidos os resultados encontrados no estudo. Primeiramente, será demonstrado o total dos tributos arrecadados pela Receita Federal do Brasil no período de 2004 a 2013 , dados informados em reais ( $R$ \$). Na sequência, será apresentada a participação dos tributos sobre o capital (IRPJ/CSLL/IRRF CAPITAL) e seu percentual de participação sobre o total de tributos arrecadados, seguido pelo gráfico de tendência do período analisado. Posteriormente, são apresentadas as análises qualitativas e, finalizando a seção, será analisada a relação entre os percentuais encontrados e os presidentes do período estudado.

A seguir, são demonstrados, pelas Tabelas 1, 2 e 3, os totais dos tributos arrecadados pela Receita Federal do Brasil no período de 2004 a 2013, discriminando os respectivos tributos. 
Tabela 1: Total dos Tributos

\begin{tabular}{lrrr}
\hline RECEITAS & $\mathbf{2 0 0 6}$ & $\mathbf{2 0 0 5}$ & $\mathbf{2 0 0 4}$ \\
\hline IMPOSTO SOBRE IMPORTAÇÃO & 10.035 .550 .493 & 9.085 .916 .070 & 9.199 .655 .078 \\
IMPOSTO SOBRE EXPORTAÇÃO & 12.481 .424 & 48.875 .267 & 75.975 .103 \\
IPI - TOTAL & 28.188 .393 .894 & 26.372 .655 .893 & 22.822 .170 .902 \\
IRPF & 8.535 .679 .611 & 7.340 .869 .979 & 6.135 .861 .879 \\
IRPJ & 56.175 .887 .178 & 51.129 .809 .676 & 38.878 .116 .046 \\
IMPOSTO S/ RENDA RETIDO NA FONTE & 72.663 .061 .324 & 66.147 .340 .085 & 57.786 .711 .424 \\
IRRF - RENDIMENTOS DO TRABALHO & 39.172 .575 .187 & 35.821 .273 .079 & 31.522 .802 .183 \\
IRRF - RENDIMENTOS DO CAPITAL & 21.321 .839 .552 & 19.991 .149 .370 & 17.280 .629 .723 \\
IRRF - REMESSAS P/ EXTERIOR & 7.448 .585 .339 & 6.184 .342 .150 & 5.574 .235 .197 \\
IRRF - OUTROS RENDIMENTOS & 4.720 .061 .217 & 4.150 .575 .509 & 3.409 .044 .312 \\
IMPOSTO S/ OPERAÇÕES FINANCEIRAS & 6.785 .974 .010 & 6.101 .644 .487 & 5.253 .182 .310 \\
IMPOSTO TERRITORIAL RURAL & 343.961 .702 & 323.599 .282 & 292.401 .793 \\
CPMF & 32.090 .257 .201 & 29.230 .370 .062 & 26.432 .323 .642 \\
COFINS & 92.474 .980 .598 & 87.902 .289 .853 & 76.481 .809 .329 \\
CONTRIBUIÇÃO PARA O PIS/PASEP & 24.276 .526 .065 & 22.045 .886 .117 & 19.344 .203 .477 \\
CSLL & 28.116 .301 .431 & 26.322 .642 .050 & 19.554 .058 .268 \\
CIDE-COMBUSTIVEIS & 7.816 .858 .504 & 7.679 .683 .998 & 7.845 .609 .169 \\
TOTAL DOS TRIBUTOS & $\mathbf{3 6 7 . 5 1 5 . 9 1 3 . 4 3 5}$ & $\mathbf{3 3 9 . 7 3 1 . 5 8 2 . 8 1 9}$ & $\mathbf{2 9 0 . 1 0 2 . 0 7 8 . 4 2 0}$ \\
\hline
\end{tabular}

Fonte: Adaptado Receita Federal do Brasil (2014).

\section{Tabela 2: Total dos Tributos}

\begin{tabular}{lrrr}
\hline RECEITAS & $\mathbf{2 0 0 9}$ & $\mathbf{2 0 0 8}$ & $\mathbf{2 0 0 7}$ \\
\hline IMPOSTO SOBRE IMPORTAÇÃO & 16.091 .944 .137 & 17.234 .845 .124 & 12.252 .868 .634 \\
IMPOSTO SOBRE EXPORTAÇÃO & 11.403 .763 & 8.259 .934 & 10.773 .579 \\
IPI - TOTAL & 30.752 .587 .525 & 39.466 .081 .106 & 33.793 .947 .185 \\
IRPF & 14.840 .322 .479 & 14.986 .453 .492 & 13.654 .809 .593 \\
IRPJ & 84.520 .591 .703 & 84.726 .295 .955 & 69.856 .190 .090 \\
IMPOSTO S/ RENDA RETIDO NA FONTE & 92.235 .589 .969 & 92.042 .309 .477 & 76.626 .461 .869 \\
IRRF - RENDIMENTOS DO TRABALHO & 52.176 .571 .294 & 51.609 .912 .835 & 42.347 .354 .190 \\
IRRF - RENDIMENTOS DO CAPITAL & 22.927 .028 .934 & 24.854 .387 .577 & 21.421 .233 .955 \\
IRRF - REMESSAS P/ EXTERIOR & 10.656 .547 .103 & 9.562 .137 .526 & 7.801 .356 .883 \\
IRRF - OUTROS RENDIMENTOS & 6.475 .442 .637 & 6.015 .871 .540 & 5.056 .516 .883 \\
IMPOSTO S/ OPERAÇÕES FINANCEIRAS & 19.243 .266 .956 & 20.340 .530 .439 & 7.833 .253 .895 \\
IMPOSTO TERRITORIAL RURAL & 474.561 .106 & 469.773 .454 & 379.222 .351 \\
CPMF & 284.786 .602 & 1.147 .843 .983 & 36.483 .136 .471 \\
COFINS & 117.886 .020 .775 & 120.801 .159 .239 & 102.462 .981 .824 \\
CONTRIBUIÇÃO PARA O PIS/PASEP & 31.755 .395 .164 & 31.598 .497 .401 & 26.709 .432 .409 \\
CSLL & 44.236 .721 .261 & 43.969 .590 .337 & 34.411 .054 .082 \\
CIDE-COMBUSTÍVEIS & 4.828 .374 .232 & 5.934 .336 .272 & 7.938 .396 .998 \\
TOTAL DOS TRIBUTOS & 457.161 .565 .674 & 472.725 .976 .215 & 422.412 .528 .980 \\
\hline
\end{tabular}

Fonte: Adaptado Receita Federal do Brasil (2014) 
Tabela 3: Total dos Tributos

\begin{tabular}{lrrrr}
\hline RECEITAS & $\mathbf{2 0 1 3}$ & $\mathbf{2 0 1 2}$ & $\mathbf{2 0 1 1}$ & $\mathbf{2 0 1 0}$ \\
\hline IMPOSTO SOBRE IMPORTAÇÃO & 37.196 .928 .877 & 31.110 .714 .003 & 26.734 .272 .036 & 21.119 .020 .307 \\
IMPOSTO SOBRE EXPORTAÇÃO & 62.507 .630 & 31.988 .619 & 12.153 .625 & 16.975 .128 \\
IPI - TOTAL & 47.101 .116 .274 & 45.927 .424 .890 & 46.917 .867 .788 & 39.990 .506 .654 \\
IRPF & 26.452 .449 .606 & 24.309 .739 .081 & 21.973 .416 .663 & 17.253 .591 .698 \\
IRPJ & 126.148 .599 .409 & 108.839 .577 .270 & 104.054 .439 .597 & 89.101 .096 .784 \\
IMPOSTO S/ RENDA RETIDO NA FONTE & 140.208 .631 .733 & 130.996 .722 .686 & 123.790 .531 .442 & 101.846 .603 .157 \\
IRRF - RENDIMENTOS DO TRABALHO & 78.819 .859 .630 & 75.106 .024 .056 & 68.825 .083 .375 & 59.823 .643 .366 \\
IRRF - RENDIMENTOS DO CAPITAL & 34.468 .514 .512 & 32.979 .847 .388 & 34.253 .556 .319 & 24.184 .822 .689 \\
IRRF - REMESSAS P/ EXTERIOR & 16.970 .971 .656 & 14.742 .926 .088 & 13.402 .165 .392 & 11.298 .617 .936 \\
IRRF - OUTROS RENDIMENTOS & 9.949 .285 .935 & 8.167 .925 .154 & 7.309 .726 .355 & 6.539 .519 .167 \\
IMPOSTO S/ OPERAÇÕES FINANCEIRAS & 29.414 .625 .434 & 30.772 .158 .444 & 31.807 .156 .515 & 26.601 .198 .154 \\
IMPOSTO TERRITORIAL RURAL & 847.843 .908 & 677.395 .295 & 602.743 .245 & 526.363 .877 \\
CPMF & & & 145.155 .323 & 119.044 .216 \\
COFINS & 201.526 .683 .818 & 174.469 .951 .616 & 158.078 .610 .536 & 139.689 .619 .348 \\
CONTRIBUIÇÃO PARA O PIS/PASEP & 51.898 .550 .019 & 46.217 .035 .198 & 41.844 .095 .789 & 40.547 .743 .394 \\
CSLL & 65.732 .057 .876 & 57.513 .998 .339 & 58.127 .068 .569 & 45.928 .344 .170 \\
CIDE-COMBUSTIVEIS & 34.859 .062 & 2.736 .147 .559 & 8.924 .070 .161 & 7.738 .163 .207 \\
TOTAL DOS TRIBUTOS & $\mathbf{7 2 6 . 6 2 4 . 8 5 3 . 6 4 6}$ & $\mathbf{6 5 3 . 6 0 2 . 8 5 3 . 0 0 1}$ & $\mathbf{6 2 3 . 0 1 1 . 5 8 1 . 2 8 8}$ & $\mathbf{5 3 0 . 4 7 8 . 2 7 0 . 0 9 5}$ \\
\hline
\end{tabular}

Fonte: Adaptado Receita Federal do Brasil (2014)

Com os dados contidos nas Tabelas 1, 2 e 3, é possível calcular o percentual de participação dos tributos sobre o capital (IRPJ/CSLL/IRRF CAPITAL) dos anos analisados:

Tabela 4: Participação dos tributos sobre o capital

\begin{tabular}{lccr}
\hline ANO & ARRECADAÇÃO TOTAL I & $\begin{array}{c}\text { RPJ/CSLL/IR } \\
\text { RF CAPITAL }\end{array}$ & \% PARTICIPAÇÃO \\
\hline 2013 & 726.624 .853 .646 & 226.349 .171 .797 & 31,15 \\
2012 & 653.602 .853 .001 & 199.333 .422 .997 & 30,5 \\
2011 & 623.011 .581 .288 & 196.435 .064 .485 & 31,53 \\
2010 & 530.478 .270 .095 & 159.214 .263 .643 & 30,01 \\
2009 & 457.161 .565 .674 & 151.684 .341 .899 & 33,18 \\
2008 & 472.725 .976 .215 & 153.550 .273 .869 & 32,48 \\
2007 & 422.412 .528 .980 & 125.688 .478 .127 & 29,75 \\
2006 & 367.515 .913 .435 & 105.614 .028 .161 & 28,74 \\
2005 & 339.731 .582 .819 & 97.443 .601 .096 & 28,68 \\
2004 & 290.102 .078 .420 & 75.712 .804 .037 & 26,1 \\
\hline
\end{tabular}

Fonte: Elaborado pelos autores

Com os resultados apresentados na Tabela 4, obteve-se o percentual de participação dos tributos sobre o capital. Em uma primeira análise, já é possível observar um crescimento constante no percentual de participação para os anos de 2004 a 2009, partindo de 26,1\% em 2004 e chegando a 33,18\% em 2009. Já a partir de 2010, o percentual de participação recua, atingindo $30,01 \%$, índice muito próximo ao de 2007. O Gráfico 1 ilustra os percentuais de participação dos tributos sobre o capital dos anos analisados: 
Gráfico 1: Escala de tendência - tributos sobre capital

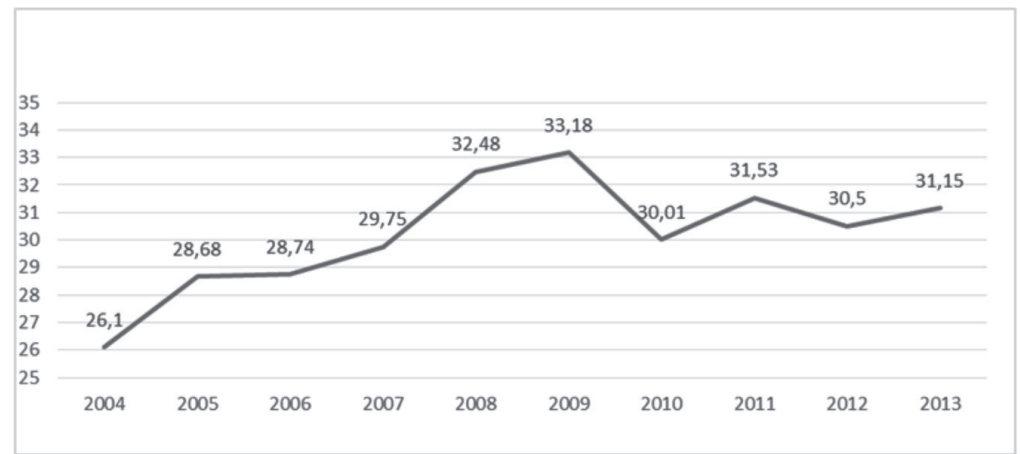

Fonte: Elaborado pelos autores

Repare que, diferentemente do ocorrido entre 2004 e 2009, a partir de 2010 os percentuais de participação encontrados demonstram oscilações, porém apresentaram a menor variação em um período de quatro anos, dentro do intervalo analisado, atingindo uma assimetria de $-0,16$ contra $-1,72$ quando comparado aos quatro primeiros anos analisados, por exemplo, uma razão que justifique esses resultados pode se dar por mudanças do governo federal em relação a sua política tributária, que apontaram, segunda a teoria aqui exposta, um maior incentivo com o passar dos anos a redistribuição, principalmente entre 2004 a 2009 e, a partir de 2010, uma maior tendência a estabilização desse percentual a um nível inferior a 2008 e 2009, atingindo uma média de $30,79 \%$ nos quatro últimos anos.

Ainda segundo a Teoria da Tributação do Capital, seria possível ao menos supor que, nos últimos quatro anos, apesar de um nível ainda elevado de tributação sobre o capital (redistribuição), ocorreu uma melhora quanto ao incentivo a investimentos, porém, com percentuais muito acima dos primeiros anos analisados. Aparentemente, trata-se de uma manutenção desse percentual de participação ou, ainda, uma tendência do governo federal a incentivar o crescimento econômico, uma vez que, em 2010, o crescimento do Produto Interno Bruto (PIB) atingiu $7,5 \%$ ante 2009 , quando ocorreu uma retração de $0,2 \%$, período em que a crise internacional se agravou. 
Contudo, quando o percentual de participação dos tributos sobre o capital é analisado levando em consideração os aspectos históricos de todo o período (2004-2013), são encontradas algumas particularidades, justificadas principalmente pelo fato de que o governo federal, mesmo que opte por eficiência ou por equidade como política econômica, poderá se deparar com cenários aos quais será preciso adaptar-se ou adotar determinada ação. Como exemplo, repare que, apesar de o governo estar ano a ano elevando a participação sobre o capital no período de 2004 a 2009 (equidade), a variação entre 2007 (29,75\%) e 2008 (32,48\%) foi a mais significativa daquele período, porém, o que justifica realmente essa maior variação não é exatamente a tendência do governo à equidade, e sim um revés em uma disputa política na qual a oposição conseguiu impedir a prorrogação da Contribuição Provisória sobre Movimentação Financeira (CPMF), o que fez com que a arrecadação dessa contribuição gerasse uma receita menor em 2008. Uma diferença de 35 bilhões que acabou sendo compensada pelo governo através da arrecadação de outros tributos, principalmente pelos tributos sobre o capital (IRPJ/ CSLL), acarretando uma maior participação percentual desses impostos com relação ao montante total.

Com relação à variação de 2009 (33,18\%), a crise financeira internacional afeta efetivamente a arrecadação total do governo, que, com o objetivo de aquecer a economia, especificamente o consumo interno, implanta incentivos fiscais no setor automobilístico e, posteriormente, de eletrônicos e linha branca, com reduções temporárias nas alíquotas do Imposto sobre Produtos Industriais (IPI), gerando uma variação negativa de 9 bilhões na arrecadação desse tributo. Contudo, uma vez que a reação do governo surtiu efeito e ocorreu a aquisição desses bens pela população, as empresas desses segmentos geraram mais IRPJ e CSLL, compensando parte desse incentivo e ampliando a participação dos tributos sobre o capital daquele exercício.

Justamente na crise internacional se justifica a variação do período de 2009 e 2010 (30,01\%) com relação à participação dos tributos sobre o capital. Se, por um lado, a arrecadação do IPI foi reduzida no exercício de 2009 devido aos incentivos fiscais, no exercício de 2010 ela apresenta crescimento também de 9 bilhões, principalmente pelo fato de a maioria 
dos incentivos ter sido extinta ou prorrogada com alíquotas superiores às inicialmente concedidas, aumentando a participação dos tributos sobre o consumo. Outro fator está na recuperação econômica do Brasil no ano de 2010 , saindo de um ano sem crescimento econômico para o maior PIB (7,5\%) desde 1986, sendo que $60 \%$ desse PIB foi devido ao consumo das famílias, o que ocasionou grande aumento na arrecadação dos tributos sobre o consumo, principalmente IPI, COFINS e PIS.

Outra questão que se procurou observar foi se os percentuais de participação dos impostos sobre o capital poderiam supor características ligadas às políticas de governo dos presidentes que exerceram ou exercem esses cargos no período estudado. Observou-se que, no mandato do presidente Lula, o percentual de participação dos impostos sobre o capital (redistribuição) elevou-se praticamente em todos os sete anos de mandato que o estudo comtempla. A exceção foi em seu último ano de mandato, quando a participação recuou para $30,01 \%$, ano posterior ao auge da crise.

Já a presidente Dilma apresentou uma média de 31,06\% de participação sobre o capital em seus três anos de mandato e o fim de uma série de crescimento percentual na participação sobre o capital, o que pode ser justificado ou por uma manutenção desse percentual, entendendo que o governo encontrou o "ótimo" ou, por haver uma maior intenção/necessidade em buscar um maior equilíbrio entre a redistribuição e a eficiência.

O fato é que, apesar de se observar uma tendência à redistribuição e equidade por parte do governo federal, por meio dos dados encontrados e segundo a Teoria da Tributação do Capital, ou pela constatação de programas sociais criados pelo governo no período pesquisado, o período da crise internacional, principalmente o período pós-crise, caracterizado por baixo crescimento econômico, com exceção de 2010, demonstra a necessidade de se equilibrar aspectos de eficiência e equidade, uma vez que é importante haver esforços para combater as desigualdades sociais em um país como o nosso, mas sem deixar de fomentar a economia. E a questão tributária está diretamente ligada com a otimização desse enorme desafio. 


\section{Conclusão}

Diante dos dados coletados pela pesquisa documental, houve o intuito de analisar qual a participação na arrecadação do IRPJ/CSLL e IRRF sobre Rendimento do Capital em relação à arrecadação total dos tributos obtidos pela Receita Federal do Brasil, no período de 2004 a 2013, buscando averiguar se existiu uma tendência a incentivar investimentos (eficiência) ou uma tendência a uma maior redistribuição (equidade).

Observou-se que, para os anos de 2004 a 2009, ocorreu uma tendência à equidade e redistribuição, segundo as teorias discutidas no presente trabalho. Já nos anos de 2010 a 2013, essa tendência de elevação na participação dos tributos sobre o capital deixou de ocorrer, gerando uma provável manutenção dos percentuais de participação desses últimos quatro anos, o que, de certa maneira, contribui para a eficiência, tendo em vista o fim do crescimento constante observado nos anos anteriores. Apesar disso, a participação dos tributos sobre o capital (IRPJ/CSLL/IRRF CAPITAL) nos últimos quatro anos apresentou elevação quando comparada aos primeiros anos da análise.

Contudo, quando o percentual de participação dos tributos sobre o capital é analisado levando em consideração os aspectos históricos de todo o período (2004-2013), são encontradas algumas particularidades, justificadas principalmente pelo fato de que o governo federal, mesmo que opte por eficiência ou por equidade como política econômica, poderá se deparar com cenários aos quais será preciso adaptar-se ou adotar determinada ação. Como exemplos, temos o fim da CPMF e a crise internacional durante o período.

Sugerem-se, para futuras pesquisas, estudos que busquem investigar uma possível relação entre a arrecadação dos tributos sobre o capital e o nível de investimento das empresas brasileiras no período aqui estudado. Espera-se que este artigo possa contribuir para uma maior discussão sobre as principais teorias que cercam o presente tema, bem como incentivar novos estudos relacionados à tributação sobre o capital. 


\section{Referências}

ATKINSON, A. B; STIGLITZ, J. E. The structure of indirect taxation and economic efficiency. Journal of Public Economics, [S.I.], v.1, n.1, p. 97-119. Oct. 1972. Disponível em: <https://cowles.econ.yale.edu/P/cp/ p03b/p0367.pdf>. Acesso em 12 ago. 2014.

BARRIONUEVO FILHO, A; LUCINDA, C. R. In: BIDERMAN, C; AVARTE, P.(Coord.). Economia do Setor Público no Brasil. Rio de Janeiro: Elsevier, 2004. p. 45-71.

BOSKIN, M. J. Tax policy and economic growth: lessons from the 1980s. Journal of Economic Perspectives, E.U.A, v. 2, n. 4 (Autumn), p. 71-9, Fall, 1988. Disponível em: <http://econ.tu.ac.th/archan/sakon/ tax policy and growth from 80s.pdf>. Acesso em 12 ago. 2014.

CORDES, J. J; SHEFFRIN, S. M. Taxation and the sectoral allocation of capital in the US. National Tax Journal. USA, v. 34, n. 34, p. 419. 1981. Disponível em: < http://www.jstor.org/stable/41862402>. Acesso em: 12 ago. 2014.

COUTINHO, D. R. Entre Eficiência e Equidade: A universalização das telecomunicações em países em desenvolvimento. Revista Direito GV 2, São Paulo-SP, v. 1, n. 21, p. 137-160. dez. 2005. Disponível em: <http://www.cebrap.org.br/ v2/files/upload/biblioteca_virtual/ COUTINHO_Entre\%20eficiencia_e_equidade.pdf>. Acesso em: 12 ago. 2014.

DESLANDES, S. F; GOMES, R; MINAYO, M. C. S. (Org). Pesquisa social: teoria, método e criatividade. 32 ed. Rio de Janeiro: Vozes, 2012.

FIANI, R. Teoria da regulação econômica: estado atual e perspectivas futuras. Rio de Janeiro. UFRJ; IE, 1998. (Texto para discussão). Disponível em: <http://www.ie.ufrj.br/grc/pdfs/teoria_da_regulacao_ economica.pdf>. Acesso em: 15 abr. 2014.

FORTIN, P. Less taxes and better taxes: principles for tax cuts and tax reform. Canadian Tax Journal, Canada, v. 48, n. 1, p. 92-100. 2000. Disponível em: <http://www.panoptica.org/seer/index.php/op/article/ download/277/299>. Acesso em: 12 ago. 2014. 
GIL, A. C. Como elaborar projetos de pesquisa. 4. ed. São Paulo: Atlas, 2002.

GRAVELLE, J. G. Capital income taxation and efficiency in the allocation of investment. National Tax Journal. E.U.A, v. 36, n. 3, p. 297. Sept. 1983. Disponível em: <http://www.jstor.org//discover/>. Acesso em: 12 ago. 2014.

LEMGRUBER, A. In: BIDERMAN, C; AVARTE, P.(Coord.). Economia do Setor Público no Brasil. Rio de Janeiro: Elsevier, 2004. p. 206230.

MARTINS, G. A; THEÓPHILO, C. R. Metodologia da investigação científica para ciências sociais aplicadas. 2 ed. São Paulo: Atlas, 2009.

RECEITA FEDERAL. Serviços: Arrecadação por Estado (mês a mês) - Anos Anteriores. Disponível em: <http://www.receita.fazenda. gov.br/Historico/Arrecadacao/PorEstado/default.htm>. Acesso em: 18 abr.2014.

REZENDE, F. Globalização, Federalismo e Tributação. Planejamento e Políticas Públicas. n. 20, dez de 1999. Disponível em:

<http://www.ipea.gov.br/agencia/images/stories/PDFs/ppp20.pdf>. Acesso em: 12 ago. 2014.

STIGLER, G. The economic theory of regulation. Bell Journal of Economics. v. 2, n. 1, p. 3-21. Spring. 1971. Disponível em:

<http://www.jstor.org/discover/10.2307/3003160?uid=3737664\&uid=2\&u id=4\&sid=21106464173363 > . Acesso em 18 abr. 2014.

VIOL, A. L. A finalidade da tributação e sua difusão na sociedade. In: Seminário de Políticas Tributárias, 2. 2005, Brasília. Disponível em: <http://www.receita.fazenda.gov.br/Publico/estudotributarios/Eventos/ Seminarioll/Texto02AFinalidadedaTributacao.pdf>. Acesso em $10 \mathrm{de}$ abr. 2014.

Artigo recebido em: 14/10/2015

Aprovado em: 16/01/2016 